\title{
Behaviour of buff-throated partridges (Tetraophasis szechenyii) during incubation, with emphasis on cooperative breeding
}

\begin{abstract}
The buff-throated partridge (Tetraophasis szechenyii) was only recently identified as a cooperative breeder. Although helpers have been observed in foraging and communal nightroosting post hatching, including provisioning, brooding, vigilance, and territorial defense, little is known about behavior relevant to cooperative efforts during incubation. Based on observations on a cooperative breeding group comprising one mating pair and one male helper, in this paper we describe shared guarding obligations that the breeding male and the male helper both assumed of the incubating female and the nest during incubation. For another cooperative breeding group that contained one mating pair and one female helper, which was a daughter from the previous year, we report a likely event of egg movement or a new nesting attempt by the philopatric daughter in response to nest predation and the loss of her mother. The findings provide insights into understanding the fitness benefit of cooperative breeding in buff-throated partridges.
\end{abstract}

Keywords: cooperative breeding group, breeding male, buff-throated partridge, philopatric daughter, brooding, territorial defense, cooperative efforts
Volume 4 Issue I - 2019

\author{
Yu Xu,' Kai Zhang,' Bin Wang,' Liang Dou, ${ }^{3}$ \\ Nan Yang, Jianghong $\operatorname{Ran}^{3}$ \\ 'School of Life Sciences, Guizhou Normal University, Guiyang, \\ China \\ ${ }^{2}$ Institute of Ecology, Key Laboratory of Southwest China \\ Wildlife Resources Conservation (Ministry of Education), China \\ West Normal University, China \\ ${ }^{3}$ Key Laboratory of Bio-Resource and Eco-Environment \\ of Ministry of Education, School of Life Sciences, Sichuan \\ University, China \\ ${ }^{4}$ Institute of Qinghai-Tibetan Plateau, Southwest Minzu \\ University, China
}

\begin{abstract}
Correspondence: Jianghong Ran, Key Laboratory of BioResource and Eco-Environment of Ministry of Education, School of Life Sciences, Sichuan University, Chengdu 610065, China, Email rjhong-0I@I63.com
\end{abstract}

Received: December 18, 2018 | Published: January 23, 2019

\section{Introduction}

Cooperative breeding is a social system that involves more than two individuals of the same species providing care for the rearing of young from a single nest or brood. ${ }^{1,2}$ This breeding system is rarely found in Galliformes, which have highly precocious young and usually provide limited parental care. ${ }^{3}$ As a cryptic Himalayan galliform species, the buff-throated partridge (Tetraophasis szechenyii) was only recently found to breed cooperatively, with breeding groups comprising one breeding pair, up to three helpers of either sex (but predominantly male) and a single set of young if present; helpers have been observed aiding foraging and communal night-roosting post hatching, including provisioning, brooding, vigilance, and territorial defense. ${ }^{4-6}$ The patterns of behaviour during incubation are fundamental to understanding social breeding systems in birds. ${ }^{1}$ For buff-throated partridges, it has been reported that only females are involved in incubation, ${ }^{7}$ and the limited available studies regarding incubation have focused predominantly on activity rhythms of attending female birds; ${ }^{8,9}$ thus, information on behaviours associated with cooperative efforts during incubation is scarce. ${ }^{4,6}$ Here, we describe incubation behaviour particularly relevant to cooperative arrangements of a cooperative breeding buff-throated partridge group comprising one mating pair and one male helper (\#2), of which the nest was constantly monitored until the eggs hatched. Based on observations of another cooperative breeding group $(\# \mathrm{G})$ that contained one mating pair and one female helper, which was a daughter from the previous year, we report a likely event of egg movement or a new nesting attempt by the philopatric daughter following nest predation and the loss of her mother.

\section{Materials and methods}

The study site was located at Pamuling $\left(30^{\circ} 06^{\prime} \mathrm{N} 101^{\circ} 11^{\prime} \mathrm{E}\right.$; Figure), Yajiang County, Ganzi Tibetan Autonomous Prefecture, Sichuan, China. This site ranged in elevation from approximately 3,900 to 4,200 $\mathrm{m}$. The site comprises mainly fir-larch forests, oak thickets, rhododendron scrubs, and a small patch of alpine meadows where a Tibetan monastery was situated (Figure). The buff-throated partridges were tame in the site, because of supplementary feeding by monks of the monastery and local people who worshiped the monastery. Group \#2 and group \#G were observed in 2006 and 2008, respectively, as part of a larger study on population ecology of buff-throated partridges. ${ }^{10}$ The mating pair from group \#2 was marked with colored leg bands during the early breeding season, and the breeding male was fitted with one necklace-transmitter; for group \#G, the breeding male and the philopatric daughter were marked with colored leg bands. In addition to marks and transmitters, we recognized groups by their exclusive territory and details of plumage on the upper tail coverts and spurs. ${ }^{4}$ Daily observations generally lasted from $15 \mathrm{~min}$ before sunrise to 15 min after sunset (We downloaded the exact data on sunrise times from www.time.ac.cn/serve/sunriseset/test.asp). One observer recorded the identity of the bird attending the nest, and incubation shifts between nest attendance and nest recess (e.g., departure times, return times, and routes of departure and return). Other observers recorded the locations and behaviour of non-incubating individuals by searching randomly using radio-tracking wherever possible. All observers tried to remain at a concealed site at a distance of approximately $10 \mathrm{~m}$ from the nest or partridges where visual observations aided by the use of the binoculars without disturbance was possible. 


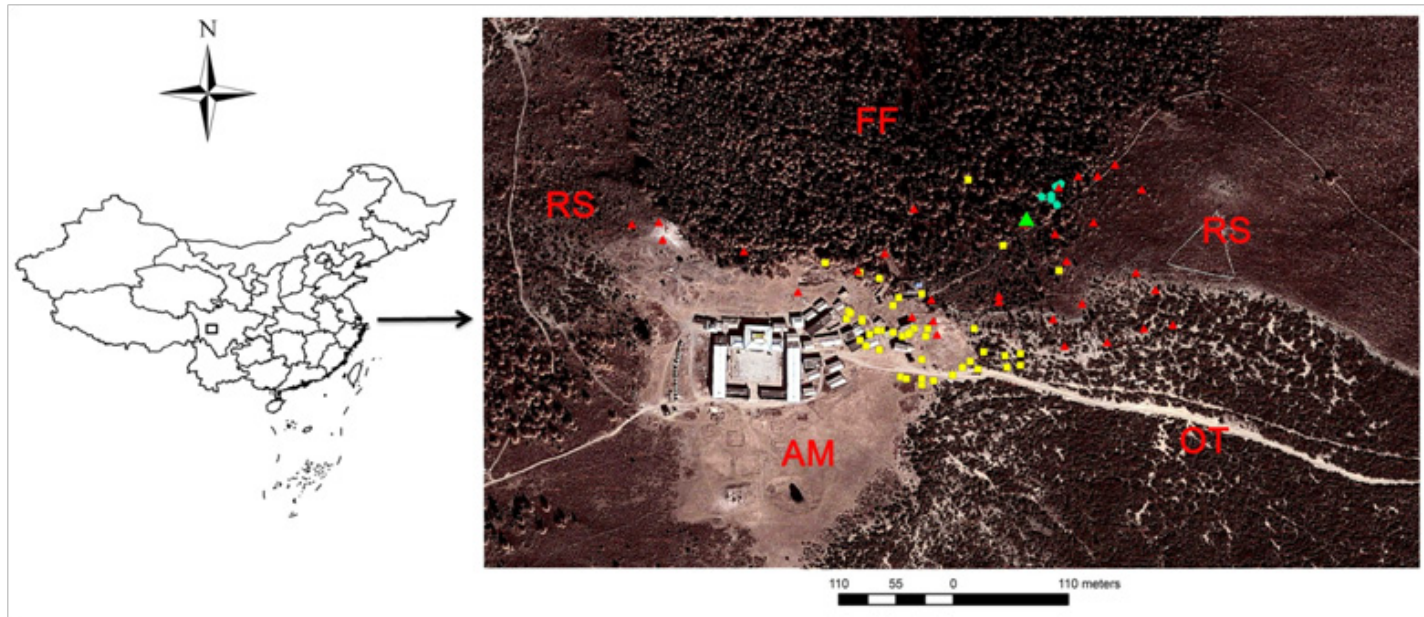

Figure Map showing the study site $\left(30^{\circ} 06^{\prime} \mathrm{N} 101^{\circ} \mathrm{II} \mathrm{I}\right)$ and nesting, feeding and night-roosting locations of group \#2 overlaid on Google imagery. The green triangle represents the nest location; yellow squares represent the locations where all group members fed together in the morning; and red triangles and blue pentagons represent the feeding and night-roosting locations of non-incubating members (i.e., the breeding male and male helper) when the female was attending the nest, respectively. Abbreviation: FF, fir-larch forests; OT, oak thickets; RS, rhododendron scrubs; AM, alpine meadows.

\section{Results}

We found the nest of group \#2 on 20 April, 2006, which was considered to be the first day of incubation because the breeding female had roosted together with her mate and the male helper for the previous two nights and no new eggs were laid on subsequent days. The nest of four eggs was built at the base of a fir tree. We started observations on incubation behaviour on the 22 April, 2006. The incubation period lasted for 24 days, with the breeding female incubating the eggs alone. While the female was attending the nest during the daytime, the mate and the male helper foraged together at $147.7 \mathrm{~m} \pm 5.1 \mathrm{SE}(n=43)$ around the nest site (Figure 1). At night, they approached the nest attended by the female, roosting on trees $34.0 \mathrm{~m} \pm 3.0 \mathrm{SE}(n=7)$ from the nest. The female left the nest at most once daily to feed, on average $18.5 \min \pm 5.6 \mathrm{SE}(n=17)$ after sunrise. The two males usually $(95.4 \%, 21 / 22)$ accompanied the female to the feeding area, which was sited approximately $125.6 \mathrm{~m} \pm 14.0 \mathrm{SE}(n=31)$ from the nest; all individuals fed together until the female returned to the nest. The female generally returned the nest after feeding for on average $51.0 \min \pm 4.9 \mathrm{SE}(n=17)$. The breeding male often $(47.1 \%$, 8/17) escorted the female back to the nest, and left after $13.2 \min \pm 3.1$ SE $(n=5)$ of vigilance. The male helper attended $50 \%$ of the events, but did not act alone.

We found a nest of group \#G on 14 May, 2008, located at the base of a rhododendron scrub. It contained four eggs that had incubated for approximately 1 week. We visited the nest daily without causing any disturbance and, on 24 May, 2008 we found the incubating female predated $3 \mathrm{~m}$ west from the nest, probably by a mammalian predator. The four eggs were missing from the nest scrape, and we did not find the eggs, nor any evidence of them (i.e., eggshell fragments), in the vicinity of the nest. For further reference, we put small stones inside the nest. When we revisited the nest 2 days later (26 May, 2008) and found one egg $2 \mathrm{~m}$ northeast from the nest with a small hole in its shell. All the reference stones had been moved out of the nest. Interestingly, we found that the philopatric daughter was incubating about $20 \mathrm{~m}$ from the nest. Despite this nesting failure, the philopatric daughter and her father remained in the territory until the next breeding season.

\section{Discussion}

This paper describes behavioural activities particularly relevant to cooperative arrangements during incubation in a breeding buffthroated partridge pair with one male helper. While the breeding female bore complete responsibility for incubation, the mate and the male helper shared guarding obligations of the female and the nest. The mate and the male helper remained together around the nest while the female was attending the nest, generally remaining within the mean territory radius defended by this species $\left(183.7 \mathrm{~m}^{11}\right)$. In particular, they were closer to the nest during the night for providing more protection for the nest and the attending female, probably because nocturnal predators were common in the study site. ${ }^{5}$ The breeding male and the male helper usually accompanied the female when she left the nest, possibly to enable her to maximize her feeding efficiency. However, the male helper contributed less than the breeding male in escorting the female back to the nest from feeding. Interestingly, this observed difference in contributions to cooperation between males of different status is contrary to that observed during foraging and in roosting nocturnally post hatching, when male helpers make a larger contribution to cooperative efforts of territorial defense, vigilance or thermal protection. ${ }^{4,5}$

For the cooperative breeding group that contained one mating pair and their philopatric daughter, we found that the philopatric daughter incubated in the vicinity of the original nest 2 days after nest predation and the loss of her mother. This phenomenon might be explained by egg moving, although this is rarely documented in avian species. ${ }^{12-15}$ We suspect that the eggs might have survived and been elsewhere following the death of the parent bird from predation, given that no eggshell fragments were observed in the vicinity of the nest after the mother had died. The egg with a small hole in its shell might have been discarded while it was being moved. The philopatric daughter might have wanted to reuse the original nest, indicated by her removing the reference stones that we placed inside the nest, but eventually abandoned it and reformed a new nest adjacent to the original site. Alternatively, the daughter might have made a new nesting attempt in the natal territory as the result of incestuous mating between her and her father, given that the predator might have consumed the eggs whole, thus leaving no eggshell remnants. ${ }^{16}$ Despite the rarity of incestuous mating, ${ }^{17}$ incest was recently reported in a cooperatively breeding group in the study site where a philopatric son mated incestuously with his mother, confirmed using genetic techniques. ${ }^{18}$ In either case, we argue for the increased probability of reproduction 
under the umbrella of cooperative breeding, despite a risk of pairing with the father, which can result in inbreeding depression or other potential costs of inbreeding. ${ }^{17}$

Our findings provide insights into understanding the fitness benefits of cooperative breeding in this species. Given the cryptic behaviour of this species in densely vegetated habitats, we suggest that further studies should make a special effort to find active nests. Using new or inexpensive technologies, such as infrared video-cameras, to investigate behaviour will enable us to gain deeper insights into the breeding ecology of this cryptic species. ${ }^{19}$

\section{Acknowledgments}

We thank the Forestry Bureau of Yajiang County and Pamuling Monastery for permission and support for the fieldwork. This study was supported by the Doctoral Foundation of Guizhou Normal University (2016).

\section{Conflicts of interests}

The authors declare that there is no conflict of interests.

\section{References}

1. Brown JL. Helping and communal breeding in birds: Ecology and evolution. Princeton, NJ: Princeton University Press; 1986.

2. Stacey PB, Koenig WD. Cooperative breeding in birds. Long-term studies of ecology and behavior. Cambridge, NY: Cambridge University Press; 1990.

3. Ligon JD, Burt DB. Evolutionary origins. In: Koenig WD, Dickinson $\mathrm{JL}$, editors. Ecology and evolution of cooperative breeding in birds. Cambridge, NY: Cambridge University Press; 2004:5-34.

4. Xu Y, Yang N, Zhang K, et al. Cooperative breeding by buff-throated partridges Tetraophasis szechenyii: a case in the Galliformes. J Ornithol. 2011;152(3):695-700.

5. Xu Y, Yang N, Ran JH, et al. Social ordering of roosting by cooperative breeding buff-throated partridges Tetraophasis szechenyii. Ethol Ecol Evol. 2013;25(3):289-297.

6. Wang B, Zhang B, Yang N, et al. Cooperative breeding of buff-throated partridges in two natural populations: Demographic comparison with a habituated population. Pak J Zool. 2017;49(2):531-536.
7. Lu TC. Buff-throated Partridges. In: Lei FM, Lu TC, editors. China Endemic Birds. Beijing: Science Press; 2006:54-60.

8. Yang N, Xu Y, Ran JH, et al. Notes on the breeding habits of the buffthroated partridge. Chin J Zool. 2009;42(2):48-51.

9. Dou L, Zhang K, Ran JH, et al. Observation on incubation behavior of the buff-throated partridge (Tetraophasis szechenyii). Sichuan J Zool. 2010;29(4):593-596.

10. Xu Y. Population ecology of Buff-throated Partridges: population density, habitat selection and breeding system. Chengdu: Sichuan University; 2011.

11. Yang N, Zhang K, Lloyd H, et al. Group size does not influence territory size and overlap in an experimental population of a cooperative breeding Galliforme species. Ardea. 2011;99(2):199-206.

12. Trost CH, Webb CL. Egg moving by two species of corvid. Anim Behav 1986;34:294-295.

13. Zheng GM, Zhao XR, Zhang ZW. Yellow-bellied Tragopan. In: Lu TC, editor. The rare and endangered game birds in China. Foochow: Fujian Science and Technology Press; 199:186-208.

14. Wiltermuth MT, Anteau MJ, Sherfy MH, et al. Nest movement by piping plovers in response to changing habitat conditions. Condor. 2009;111(3):550-555.

15. O'Connell DP, Power A, Doyle S, et al. Nest movement by little terns (Sternula albifrons) and ringed plovers (Charadrius hiaticula) in response to inundation by high tides. Ir Birds. 2014;10(1):19-22.

16. Staller EL, Palmer WE, Carroll JP, et al. Identifying predators at northern bobwhite nests. J Wildl Manage. 2005;69(1):124-132.

17. Koenig WD, Haydock J. Incest and incest avoidance. In: Koenig WD, Dickinson JL, editors. Ecology and evolution of cooperative breeding in birds. Cambridge, NY: Cambridge University Press; 2004:142-156.

18. Liu Q. Analysis of cooperative breeding and population genetics of Buffthroated Partridges based on molecular markers. Chengdu: Sichuan University; 2017.

19. $\mathrm{Xu} \mathrm{Y}$, Ellis Felege SN, Carroll JP. Parental risk-taking at natural northern bobwhite nests. Avian Biol Res. 2017;10(2):69-75. 